\title{
Toxicological evaluation of endophyte-infected perennial ryegrass straw to Japanese Black steers
}

\author{
S. MIYAZAKI ${ }^{1}$, T. IKEDA ${ }^{2}$, M. HANAZUMI ${ }^{2}$, Y. FUKUMOTO ${ }^{3}$, T. YAMATA ${ }^{3}$, O. MIKAMI ${ }^{1}$, N. YAMANAKA ${ }^{1}$, H. MURATA $^{1}$, \\ N. SHIMADA ${ }^{1}$, E. ISHIKURO ${ }^{3}$ \\ ${ }^{1}$ National Institute of Animal Health, Tsukuba, Ibaraki 305-0856 Japan \\ ${ }^{2}$ Japan Scientific Feeds Association, Narita, Chiba 286-0133 Japan \\ ${ }^{3}$ Fertilizer and Feed Inspection Services, Saitama, Saitama 330-9733 Japan \\ s.miyazaki@affrc.go.jp
}

\begin{abstract}
Experimental feeds containing 0, 500, 1000, 1500 or $2000 \mathrm{ppb}$ of lolitrem B derived from perennial ryegrass straw were fed to 9 month-old Japanese Black steers (average liveweight $180 \mathrm{~kg}$ ) to determine their threshold level of lolitrem B. Steers received feeds containing 1000, 1500 and $2000 \mathrm{ppb}$ of lolitrem B showed signs of ryegrass staggers after 2 to 7 weeks of feeding. The lowest observed adverse effect level (LOAEL) of lolitrem B was approximately $24 \mu \mathrm{g} / \mathrm{kg}$ body weight per day. Only small amounts of lolitrem B residue were detected in muscle, liver, kidney and cerebrum. In contrast, approximately $100 \mathrm{ng} / \mathrm{g}$ of lolitrem B was detected in perirenal fat of steers with ryegrass staggers.

Keywords: Lolitrem B, Japanese Black cattle, ryegrass staggers, muscle, fat
\end{abstract}

\section{Introduction}

From the latter half of 1990 s, we have experienced ryegrass staggers cases in cattle and horses fed imported perennial ryegrass straw (Miyazaki et al. 2001) from Oregon, USA. Lolitrem B concentrations in the straws ranged between $972 \mathrm{ppb}$ and $3740 \mathrm{ppb}$. The threshold levels of lolitrem B for toxicity were reported as $1800-2000 \mathrm{ppb}$ in the total diet (Tor-Agbidye et al. 2001) for cattle. Even though the concentrations of lolitrem B were lower than the proposed threshold in almost all clinical cases, endophyte-infected perennial ryegrass straw was suspected as the cause of the disorders from the clinical signs and epidemiological findings. The sensitivity of the cattle to the endophyte toxins might be due to differences between strains, age, sex or other factors.

Table 1 Days of feeding after which signs of ryegrass staggers appeared in Japanese Black steers fed 1000, 1500 or 2000 ppb lolitrem B.

\begin{tabular}{cccc}
\hline $\begin{array}{c}\text { Group } \\
(\mathrm{ppb})\end{array}$ & $\begin{array}{c}\text { Animal } \\
\text { No. }\end{array}$ & $\begin{array}{c}\text { Appearance of } \\
\text { staggers (days) }\end{array}$ & $\begin{array}{c}\text { Day of } \\
\text { autopsy }\end{array}$ \\
\hline 1000 & 1 & - & 51 \\
& 2 & 49 & 51 \\
& 3 & 37 & 51 \\
1500 & 1 & - & 28 \\
& 2 & 17 & 28 \\
& 3 & 15 & 28 \\
2000 & 1 & 14 & 22 \\
& 2 & 14 & 22 \\
& 3 & 14 & 22 \\
\hline
\end{tabular}

Another endophyte problem of interest is the public health significance of the endophyte toxins. In a previous study, we reported that lolitrem B was not detected in muscle, liver, kidney, lung and cerebrum of the Japanese Black cow showing signs of ryegrass staggers. On the other hand, perirenal fat tissue of the cow with ryegrass staggers contained $200 \mathrm{ng} / \mathrm{g}$ of lolitrem B (Miyazaki et al. 2004). This observation indicates that lolitrem $\mathrm{B}$ does not accumulate in major edible parts of beef cattle. Therefore, the neurotoxic effect of lolitrem B on humans eating the beef is unlikely. However, further research is needed to clarify the fate of lolitrems in the cattle.

We carried out a feeding experiment to examine the sensitivity of the Japanese Black cattle to lolitrem B, using perennial ryegrass straw containing lolitrem B. We assumed that the sensitivity of Japanese Black cattle to lolitrem B might be higher than the other strains of cattle. Furthermore, lolitrem B concentrations of several animal tissues were determined to determine the fate of lolitrem B in Japanese Black cattle.

\section{Methods}

Perennial ryegrass straws containing $0 \mathrm{ppb}$ or $3000 \mathrm{ppb}$ of lolitrem B, prepared by chopping and mixing of the straw samples collected in autumn of 2005, were imported form Oregon, USA.

Nine months old Japanese Black steers were divided into five groups of three animals. Groups were fed zero or about 500, 1000, 1500 and $2000 \mathrm{ppb}$ of lolitrem B. Experimental feeds

Table 2 Average daily body weight gain (DG) of Japanese Black steers fed lolitrem B containing feeds.

\begin{tabular}{cccc}
\hline $\begin{array}{c}\text { Group } \\
(\mathrm{ppb})\end{array}$ & $\begin{array}{c}\text { Animal } \\
\text { No. }\end{array}$ & $\begin{array}{c}\text { Duration of. } \\
\text { experiment (days) }\end{array}$ & $\begin{array}{c}\mathrm{DG} \\
(\mathrm{kg})\end{array}$ \\
\hline 0 & 1 & 100 & 0.91 \\
& 2 & 100 & 0.68 \\
& 3 & 100 & 0.38 \\
500 & 1 & 96 & 0.04 \\
& 2 & 96 & 0.47 \\
& 3 & 96 & 0.63 \\
1000 & 1 & 51 & 0.54 \\
& 2 & 51 & 0.45 \\
& 3 & 51 & 0.13 \\
1500 & 1 & 28 & 0.51 \\
& 2 & 28 & 0.06 \\
& 3 & 28 & 0.15 \\
2000 & 1 & 22 & 0.00 \\
& 2 & 22 & 0.40 \\
& 3 & 22 & -0.19 \\
\hline
\end{tabular}


Table 3 Lolitrem B consumption ( $\mu \mathrm{g} / \mathrm{kg}$ BW per day) of Japanese Black steers fed lolitrem B containing feeds.

\begin{tabular}{|c|c|c|c|c|c|c|c|c|c|c|c|c|c|c|}
\hline \multirow[t]{2}{*}{ Group } & \multirow{2}{*}{$\begin{array}{c}\text { Animal } \\
\text { No. }\end{array}$} & \multicolumn{13}{|c|}{--------------- Duration of experiment (weeks) --------------- } \\
\hline & & 1 & 2 & 3 & 4 & 5 & 6 & 7 & 8 & 9 & 10 & 11 & 12 & 13 \\
\hline \multirow[t]{3}{*}{500} & 1 & 11.0 & 11.6 & 10.4 & 11.1 & 10.9 & 8.9 & 11.0 & 9.4 & 11.1 & 11.3 & 12.4 & 11.5 & 11.2 \\
\hline & 2 & 13.0 & 13.7 & 13.0 & 13.6 & 13.6 & 13.8 & 13.6 & 13.6 & 13.4 & 13.4 & 13.6 & 13.6 & 13.5 \\
\hline & 3 & 10.3 & 11.7 & 12.5 & 11.6 & 10.9 & 11.9 & 12.5 & 13.1 & 12.2 & 13.1 & 13.0 & 12.4 & 12.5 \\
\hline \multirow[t]{3}{*}{1000} & 1 & 21.8 & 23.8 & 26.8 & 26.2 & 26.1 & 25.8 & 25.7 & 26.9 & & & & & \\
\hline & 2 & 22.0 & 24.0 & 23.1 & 20.6 & 19.7 & 21.8 & 24.1 & 26.4 & & & & & \\
\hline & 3 & 24.7 & 22.0 & 22.4 & 21.9 & 22.6 & 22.4 & 24.0 & 26.3 & & & & & \\
\hline \multirow[t]{3}{*}{1500} & 1 & 31.0 & 34.4 & 33.3 & 33.2 & & & & & & & & & \\
\hline & 2 & 41.1 & 34.5 & 39.3 & 37.9 & & & & & & & & & \\
\hline & 3 & 35.9 & 32.5 & 32.8 & 34.8 & & & & & & & & & \\
\hline \multirow[t]{3}{*}{2000} & 1 & 50.2 & 40.3 & 40.1 & & & & & & & & & & \\
\hline & 2 & 43.9 & 45.3 & 41.6 & & & & & & & & & & \\
\hline & 3 & 41.4 & 32.3 & 34.1 & & & & & & & & & & \\
\hline
\end{tabular}

consisted of $67 \%$ of straw, $24 \%$ commercial concentrated feed for beef cattle and $9 \%$ soybean meal, and these were fed at $2.4 \%$ of the body weight of the animals to obtain a daily weight gain of $0.4 \mathrm{~kg}$ according to the Japanese Feeding Standard for Beef Cattle (Ministry of Agriculture, Forestry and fisheries, Japan, 2000). Final concentrations of lolitrem B in the experimental feeds were adjusted by mixing straws containing 0 and $3000 \mathrm{ppb}$ of lolitrem B. Concentrations of Lolitrem B in the feeds were determined by official high-performance liquid chromatographic (HPLC) method recommended by the Ministry of Agriculture, Forestry and Fishery, Japan.

Clinical signs of ryegrass staggers and feed consumption were observed everyday. Body weight was measured once a week. Blood, rumen fluid and urine samples were collected periodically throughout the experiment. Blood samples were collected from jugular vein. Rumen fluids were collected by means of oral tubing. Urine samples were collected at autonomic discharge. Severity of ryegrass staggers symptom was graded according to the index of Fisher et al. (2004). Animals were submitted to pathological examinations when grade 2 ryegrass staggers was observed. Animals without signs of ryegrass staggers received experimental feeds for 13 weeks and were then autopsied for pathological observation. At autopsy, tissues for histopathological examinations and lolitrem B analyses were collected.

Serum glucose, aspartate aminotransferase (AST), alkaline phosphatase, gamma-glutamyl transpeptidase, lactate dehydrogenase $(\mathrm{LDH})$, creatine kinase $(\mathrm{CK})$, total protein, albumin, globulin, urea nitrogen, creatinine, total bilirubin, sialic acid, calcium, inorganic phosphorus, magnesium, total cholesterol and triglycerides were determined by auto analyser. Serum sodium, potassium and chloride were determined by ion meter. Blood cell counts, haemoglobin and haematocrit were measured by blood cell counter. Rumen volatile fatty acid (VFA) compositions were determined by gas chromatography.

Lolitrem B concentrations in the collected tissues were determined by HPLC and confirmed by HPLC mass-spectrometry according to the method of Miyazaki et al. (2004). Collected organs and tissues were examined by routine histopathological procedures (Mikami et al. 2005).

\section{Results and Discussion}

Animals in the $2000 \mathrm{ppb}$ group showed signs of ryegrass staggers after 14 days of feeding (Table 1). They showed tremors in gluteal muscle and limbs and a staggering gait. These animals were autopsied on the 22 nd day of the experiment. Two steers of 1500 group showed tremors within 17 days of feeding. Animals of $1500 \mathrm{ppb}$ group were autopsied on the 28th day of feeding. Furthermore, two animals in the 1000 ppb group expressed mild tremors by the 49th day of feeding. Animals of $1000 \mathrm{ppb}$ group were autopsied on the 51 st day of the experiment. One steer (No. 1 ) in the $500 \mathrm{ppb}$ group showed difficulties in standing from the 40th day of the experiment. Swelling and pain around its hocks were observed. However, this animal showed no tremors in its limbs. Therefore, this case was not considered to be ryegrass staggers. Animals of $0 \mathrm{ppb}$ and $500 \mathrm{ppb}$ groups were autopsied in the 13th week of the experiment.

Average daily body weight gain of the animals was shown in Table 2. Animals with signs of ryegrass staggers showed poor body weight gain. Onset of the poor growth preceded the onset of signs of ryegrass stagger (Fig. 1).

Pathological observations of the experimental animals detected no ryegrass staggers specific lesions including the central nervous system. Our results are consistent with the previous report for ryegrass staggers in sheep (Clegg \& Watson 1960). On the other hand, Munday \& Mason (1967) observed Purkinje's cells degeneration. Pearson et al. (1996) also observed degenerated Purkinje's cells in cerebellum of the calf consumed perennial ryegrass containing $3700 \mathrm{ppb}$ of lolitrem $\mathrm{B}$. The significance of these lesions in animals affected by ryegrass staggers requires further study.

No abnormal values for blood biochemical parameters were found in animals affected by ryegrass staggers. Although, elevated activities of serum AST, CK and LDH were observed in the severe cases of ryegrass staggers (Pearson et al. 1996; Nakamine et al. 1998; Enomoto \& Miyazaki 1999), changes in muscle-associated enzyme activities could be attributed to the skeletal muscle damage of these animals when falling. Our results confirmed that blood biochemical parameters are not directly affected by lolitrem B. 
Table 4 Lolitrem B (ng/g) concentrations in tissues of Japanese Black steers fed lolitrem B containing feeds. ND - not detected.

\begin{tabular}{|c|c|c|c|c|c|}
\hline Group & Animal No. & Fat & Liver & Kidney & Muscle \\
\hline \multirow[t]{4}{*}{0} & 1 & ND & ND & ND & ND \\
\hline & 2 & ND & ND & ND & ND \\
\hline & 3 & ND & ND & ND & ND \\
\hline & Average & ND & ND & ND & ND \\
\hline \multirow[t]{4}{*}{500} & 1 & 167 & 5 & ND & ND \\
\hline & 2 & 57 & ND & ND & ND \\
\hline & 3 & 82 & ND & ND & ND \\
\hline & Average & 102 & 2 & ND & ND \\
\hline \multirow[t]{4}{*}{1000} & 1 & 84 & ND & ND & 5 \\
\hline & 2 & 93 & ND & 14 & ND \\
\hline & 3 & 109 & ND & ND & ND \\
\hline & Average & 95 & ND & 5 & 2 \\
\hline \multirow[t]{4}{*}{1500} & 1 & 99 & ND & 10 & ND \\
\hline & 2 & 151 & ND & 6 & ND \\
\hline & 3 & 127 & 2 & ND & 10 \\
\hline & Average & 126 & 1 & 5 & 3 \\
\hline \multirow[t]{4}{*}{2000} & 1 & 114 & ND & 2 & ND \\
\hline & 2 & 160 & 5 & ND & ND \\
\hline & 3 & 92 & 1 & ND & 10 \\
\hline & Average & 122 & 2 & 1 & 3 \\
\hline
\end{tabular}

VFA compositions and $\mathrm{pH}$ of rumen fluids did not changed during the feeding experiment. Fisher et al. (2004) reported that ruminal $\mathrm{pH}$, total VFA, and $\mathrm{NH}_{3}-\mathrm{N}$ were not affected by increasing lolitrem $\mathrm{B}$ concentration in the feed. These findings indicate that the chemicals contained in the endophyte-infected perennnial ryegrass have no effects on rumen functions even when sufficient lolitrem B to induce ryegrass staggers was consumed.

Actual amounts of lolitrem B consumed by the experimental

Figure 1 Body weight gain of Japanese Black steers fed $1000 \mathrm{ppb}$ of lolitrem B. Vertical arrows indicate the time of the day on which signs of ryegrass staggers appeared.

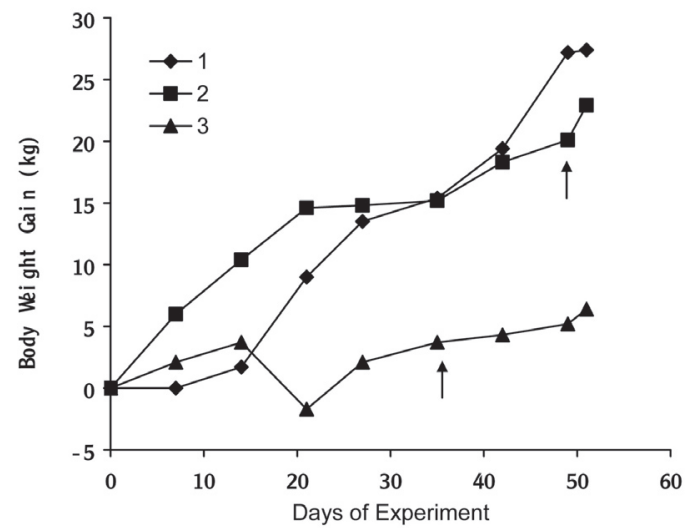

animals were calculated form their body weights and feed consumption (Table 3). As shown in Table 3, lolitrem B consumption was increased in proportion to concentrations of lolitrem B in the feeds. Results of this feeding experiment suggest that approximately $24 \mu \mathrm{g} / \mathrm{kg}$ body weight (BW) per day of lolitrem B can produce ryegrass staggers in Japanese Black steers.

As shown in Table 4, only small amounts of lolitrem B were detected in muscle ( $M$. longissimus thoracis), liver and kidney of steers with ryegrass staggers. In contrast, perirenal fat tissues of steers showing ryegrass staggers symptom contained approximately100 ng/g of lolitrem B. These results were essentially comparable to the previous report (Miyazaki et al. 2004). These observations indicate that lolitrem B from beef will not have a toxic effect on humans. However, we have no information on the metabolism of lolitrems in ruminants as we measured only intact lolitrem B in animal tissues in this study. Until the metabolism of lolitrems in cattle and the toxicity of metabolites are investigated, we will not be able to guarantee the safety of the products from cattle fed grass containing lolitrems.

The concentration of lolitrem B in perirenal fat of steers fed 2000, 1500 or $1000 \mathrm{ppb}$ of lolitrem B were comparable, at approximately $100 \mathrm{ng} / \mathrm{g}$, and the experiment was terminated at the time signs of staggers appeared, this being 22 and 51 days for the $2000 \mathrm{ppb}$ and the $1000 \mathrm{ppb}$ groups, respectively. This observation suggests the possibility that ryegrass staggers symptoms might appear when accumulated lolitrem B reached the threshold level. Mantle (1983) reported enhanced unstimulated release of excitatory neurotoransmitters in sheep showing signs of ryegrass 
staggers. Knaus et al. (1994) and McLeay et al. (1999) noted the interaction of lolitrems with high-conductance calcium-activated $\mathrm{K}^{+}$channels. However, details of the biological activities of lolitrems and the mechanisms for the induction of ryegrass staggers are still not clear. The present findings suggest possible avenues worth pursuing to elucidate the mechanism by which ryegrass staggers is induced in animals.

In conclusion, the lowest observed adverse effect level of lolitrem B in Japanese Black steers was estimated to be $24 \mu \mathrm{g} / \mathrm{kg}$ $\mathrm{BW}$ per day. Another feeding experiment is in progress to confirm these observations. The effects of lolitrem B on Japanese Black cows should also be examined because perennial ryegrass straw is their main feed during breeding in Japan. Furthermore, the metabolism of lolitrems in cattle should be examined to ensure the safety of animal products.

\section{ACKNOWLEDGEMENTS}

This study was funded by a Grant-in-Aid (research project for utilising advanced technologies in agriculture, forestry and fisheries, No. 1721) by the Ministry of Agriculture, Forestry and Fisheries of Japan. We also gratefully acknowledge Dr. A.M. Craig, Oregon State University, for his helpful discussions. Ryegrass straws used in this study were kindly prepared by US National Hay Association, Export Processors Committee, Oregon Agricultural Fiber Association and Anderson Hay \& Grain Co., Inc.

\section{REFERENCES}

Clegg, F.G.; Watson, W.A. 1960 Ryegrass staggers in sheep. The Veterinary Record 72: 731-733.

Enomoto, S.; Miyazaki, S. 1999. Endophyte intoxication in Japanese Black cattle fed ryegrass straw imported from the U.S.A. Journal of Livestock Medicine (Kachikushinnryo) 46: 421-427 (In Japanese with English summary).

Fisher, M.J.; Bohnet, D.W.; Ackerman, C.J.; Schauer, C.S.; DelCurto, T.; Craig, A.M.; Vanzant, E.S.; Harmon, D.L.; Schrick, F.N. 2004. Evaluation of perennial ryegrass straw as a forage source for ruminants. Journal of Animal Science 82: $2175-2184$.

Knaus, H.-G.; McManus, O.B.; Lee, S.H.; Schmalhofer,
W.A.; Garcia-Calvo, M.; Helms, L.M.H.; Sanchez, M.; Giangiacomo, K.; Reuben, J.P.; Smith, A.B.; Kaczorowski, G.J.; Garcia, M.L. 1994. Tremorgrnic indole alkaloids potently inhibit smooth muscle high-conductance calciumactivated potassium channels. Biochemistry 33: 5819-5828.

Mantle, P.G. 1983. Amino acid neurotransmitter release from cerebrocortical synaptosomes of sheep with ryegrass staggers in New Zealand. Research in Veterinary Science 34: 373-375.

Mcleay, L.M.; Smith, B.L.; Munday-Finch, S.C. 1999. Tremorgenic mycotoxins paxilline, penitrem and lolitrem B, the non-tremorgenic 31-epilolitrem B and electromyographic activity of the reticulum and rumen of sheep. Research in Veterinary Science 66: 119-127.

Mikami, O.; Nakajima, H.; Kawashima, K.; Yoshii, M.; Nakajima, Y. 2005. Nonsuppurative myocarditis caused by porcine circovirus type 2 in a weak-born piglet. Journal of Veterinary Medical Science 67:735-738.

Miyazaki, S.; Fukumura, M.; Yoshioka, M.; Yamanaka, N. 2001. Detection of endophyte toxins in the imported ryegrass straw. Journal of Veterinary Medical Science 63: 1013-1015.

Miyazaki, S.; Ishizaki, I.; Ishizaka, M.; Kanbara, T.; IshiguroTakeda, Y. 2004. Lolitrem B resdue in fat tissues of cattle consuming endophyte-infected perennial ryegrass straw. Journal of Veterinary Diagnostic Investigations 16: 340-342.

Munday, B.L.; Mason, R.W. 1967. Lesions in ryegrass staggers in sheep. Australian Veterinary Journal 43: 598-599.

Nakamine, M.; Asato, H.; Koshimoto, H.; Ono, M.; Nakamura, M.; Nitta, Y.; Shoji, K.; Shirai, Y.; Miyazaki, S. 1998. Ryegrass staggers suspected clinical cases in Japanese Black cattle consuming imported perennial ryegrass straws. Journal of Clinical Veterinary Medicine (Rinshojyuui) 16: 38-45 (In Japanese).

Pearson, E.G.; Andreasen, C.B.; Blythe, L.L.; Craig, A.M. 1996. Atypical pneumonia associated with ryegrass staggers in calves. Journal of American Veterinary Medical Association 209: 1137-1142.

Tor-Agbidye, J.; Blythe, L.L.; Craig, A.M. 2001. Correlation of endophyte toxins (ergovaline and lolitrem B) with clinical disease: Fescue foot and perennial ryegrass staggers. Veterinary and Human Toxicology 43: 140-146. 